\title{
A Simulation Study of Self-Extinguishing Cigarettes*
}

\author{
by \\ Bernhard Eitzinger \\ WFT Research, Fabrikstraße 20, 4050 Traun, Austria
}

\section{SUMMARY}

In some parts of the USA and in Canada smouldering cigarettes are required to extinguish if placed on a certain number of layers of filter paper. This is usually achieved by the use of bands on the cigarette paper, which reduce oxygen diffusion into the cigarette. From a smoker's perspective, however, it is desirable that a cigarette does not extinguish if left to smoulder, for example, in an ash tray. To facilitate the design of papers for such cigarettes the influence of various cigarette parameters on self-extinguishment is investigated by numerical simulation of a onedimensional cigarette model, which describes the main thermodynamic behaviour of smouldering cigarettes. The tobacco density, the tobacco heat capacity, the width of the bands on the cigarette paper and the heat released during combustion are chosen as parameters whose influence on the required oxygen diffusion constant of the bands on the cigarette paper is investigated. As these parameters are subject to a certain variation, it is assumed that the parameters are independently normally distributed. Based on this assumption the probability that a cigarette with given mean parameter values will extinguish, is calculated numerically. The results show that the admissible range of diffusion constants for the bands on the cigarette paper is in general quite small and it is reduced even further if statistical variations of the cigarette parameters are considered.

The results provide guidelines for the appropriate choice of the diffusion constant of the bands on the cigarette paper such that the cigarettes comply with legal requirements and do not extinguish during normal smoking. [Beitr. Tabakforsch. Int. 22 (2006) 79-87]

\section{ZUSAMMENFASSUNG}

In einigen Teilen der USA und in Kanada wird für die Herstellung von Zigaretten gefordert, dass diese von selbst verlöschen, wenn man sie glimmend auf eine Unterlage bestehend aus einer vorgegebenen Anzahl von Filterpapieren legt. Dies erreicht man üblicherweise dadurch, dass man die Zigaretten mit Papierbändern mit reduzierter Diffusionskonstante ausstattet. Aus Sicht des Rauchers aber ist es wünschenswert, dass eine Zigarette nicht ausgeht, während sie zum Beispiel in einem Aschenbecher glimmt. Um das Design von Papieren, die solchen Ansprüchen gerecht werden, zu vereinfachen, wird in einer Simulationsstudie der Einfluss verschiedener Parameter auf die Selbstverlöschung mit Hilfe eines eindimensionalen Zigarettenmodells untersucht. Dieses Modell beschreibt die wesentlichen thermodynamischen Vorgänge in einer glimmenden Zigarette. Untersucht wird der Einfluss der Tabakdichte, der Wärmekapazität des Tabaks, der Breite der Bänder und der Verbrennungswärme auf die benötigte Diffusionskonstante im Bereich der Bänder. Unter der Annahme, dass diese Parameter unabhängig normalverteilt sind, wird numerisch die Wahrscheinlichkeit berechnet, dass eine zufällig ausgewählte Zigarette von selbst verlöscht. Die Ergebnisse zeigen, dass der Bereich zulässiger Diffusionskonstanten für die Bänder am Zigarettenpapier im allgemeinen recht klein ist und dass die Berücksichtigung statistischer Schwankungen diesen Bereich noch erheblich reduziert.

Aus dem Ergebnis lassen sich Richtlinien ableiten, mit deren Hilfe geeignete Diffusionskonstanten für die Bänder des Zigarettenpapiers gewählt werden können, sodass die Zigarette zwar den gesetzlichen Vorgaben entspricht, aber trotzdem nicht während des normalen Rauchens von selbst verlöscht. [Beitr. Tabakforsch. Int. 22 (2006) 79-87]

\section{RESUME}

Dans certaines parties des Etats Unis ainsi qu'au Canada il est requis que les cigarettes en combustion s'éteignent spontanément lorsqu'elles sont déposées sur un nombre défini de feuilles de papier à cigarette. Ceci est généralement obtenu par l'utilisation de bandes sur le papier à cigarette qui réduisent la diffusion d'oxygène dans la 
cigarette. Pour les fumeurs, il est cependant souhaitable qu'une cigarette ne s'éteigne pas spontanément lors de la combustion libre dans un cendrier, par exemple. Afin de faciliter la conception de papiers qui répondent à ces exigences, l'influence de différents paramètres des cigarettes sur l'extinction spontanée a été examinée à l'aide d'un modèle de cigarette à une seule dimension décrivant les principaux processus thermodynamiques d'une cigarette en combustion. La densité du tabac, la capacité thermique du tabac, la largeur des bandes et la chaleur de combustion ont été choisies comme paramètres dont l'influence sur la constante de diffusion d'oxygène nécessaire dans la zone des bandes a été analysée. En supposant que ces paramètres soient distribués normalement et indépendamment, la probabilité qu'une cigarette à paramètres moyens donnés s'éteigne spontanément est calculée de façon numérique. Les résultats montrent que la gamme admissible des constantes de diffusion des bandes sur le papier à cigarette est en général très limitée et elle est encore plus réduite si les variations statistiques des paramètres des cigarettes sont prises en considération.

Les résultats donnent des directives grâce auxquelles il sera possible de choisir une constante de diffusion adéquate pour les bandes de papier à cigarettes, afin que les cigarettes soient en conformité avec la législation et ne s'éteignent pas spontanément durant le fumage normale. [Beitr. Tabakforsch. Int. 22 (2006) 79-87]

\section{INTRODUCTION}

Some parts of the USA and also recently Canada have introduced legislation that cigarettes have to show a reduced propensity of igniting foreign objects. This is checked by a standardized test (1). Smouldering cigarettes are placed on 10 layers of filter paper and out of a sample of 40 cigarettes more than a given percentage, typically $75 \%$, are required to extinguish before the smouldering cone reaches the tipping paper. The testing of a single cigarette will be referred to as the ignition strength test.

Many commercially available cigarettes which pass this test are equipped with circumferential bands on the cigarette paper and previous investigations have shown that the oxygen diffusion constant of these bands is a critical parameter for passing the test (2,3). In addition a method for measuring the diffusion constant of paper has recently become available (4). A too conservative design of these bands, however, causes the cigarette to extinguish not only on the filter paper but also during smouldering in the ash tray. The frequent relighting of cigarettes is inconvenient to the smoker and relighting may also be harmful to smokers, as it is known that the first puff contains high levels of certain smoke compounds, e.g. formaldehyde $(5,6)$. Therefore the propensity to extinguish during smouldering is assessed in a non-standardized test, where a sample of 40 cigarettes is left smouldering without substrate in a horizontal position and the percentage of cigarettes exhibiting a full-length burn is reported. We will arbitrarily set the lower limit for this percentage to $75 \%$. The testing of a single cigarette will be referred to as the free-burn test. To investigate by numerical simulation how cigarette papers can be designed so that both tests are passed simul- taneously, a mathematical model of a smouldering cigarette will be taken from (7) and adapted to the specific situation. While there are many models for smouldering cigarettes available, for example in $(8,9)$ and in the review by MURAMATSU (10), we will require a sufficiently simple model such that it can be simulated quickly. Nevertheless it is important that the thermodynamic behaviour of smouldering cigarettes is described fairly accurately, because, as is pointed out in (11), self-extinguishment is to a large extent a thermo-physical process. Numerical values for the model parameters will be taken from various sources $(7-9,12-14)$. The effect of several model parameters on the self-extinguishment will be investigated, such that for given cigarette parameters the appropriate range of oxygen transfer coefficients for the bands on the cigarette paper can be easily determined. As the chosen parameters are subject to some variation from cigarette to cigarette we will assume that the parameters are independently normally distributed and the probability that a randomly chosen cigarette will pass the tests will be calculated.

\section{MATHEMATICAL MODEL}

We start with a spatially one-dimensional model of a smouldering cigarette, similar to the one proposed in (7). The meaning of all variables and the values used for the simulation of the ignition strength test and the free-burn test are given in Table 1 . The energy equation

$$
\begin{aligned}
\rho_{\mathrm{Tob}} c_{p} \frac{\partial T}{\partial t}= & \lambda \frac{\partial^{2} T}{\partial x^{2}}+\alpha \frac{2}{r_{0}}\left(T_{\infty}-T\right) \\
& +\varepsilon \sigma F \frac{2}{r_{0}}\left(T_{\infty}^{4}-T^{4}\right)-q \frac{\partial \rho_{\mathrm{Tob}}}{\partial t}
\end{aligned}
$$

describes the change in temperature due to conduction along the tobacco rod, heat losses to the surroundings due to convection and radiation and a heat source due to the combustion reaction. The heat transfer coefficient $\alpha$ is assumed constant along the tobacco rod, but its value depends on the mode of smouldering. For free smouldering the value is set to $9.68 \mathrm{~W} / \mathrm{m}^{2} \mathrm{~K}$ and for smouldering on a substrate it is set to $17.44 \mathrm{~W} / \mathrm{m}^{2} \mathrm{~K}$ to account for the increased heat loss caused by the contact with the substrate. As is common for models of smouldering cigarettes, the flow inside and outside the cigarette is neglected and a single temperature for solid phase and gas phase is used (9). The oxygen transport equation

$$
\begin{aligned}
\phi \frac{\partial\left(\rho_{\mathrm{Gas}} w_{\mathrm{O}_{2}}\right)}{\partial t}= & D_{\mathrm{Tob}} \frac{\partial}{\partial x}\left(\phi \rho_{\mathrm{Gas}} \frac{\partial w_{\mathrm{O}_{2}}}{\partial x}\right) \\
& +\gamma D_{\mathrm{Pap}} \phi \rho_{\mathrm{Gas}} \frac{2}{r_{0}}\left(w_{\mathrm{O}_{2}, \infty}-w_{\mathrm{O}_{2}}\right)+k \frac{\partial \rho_{\mathrm{Tob}}}{\partial t}
\end{aligned}
$$

contains terms for the diffusion of oxygen along the tobacco rod, the transport of oxygen through the cigarette paper and the consumption of oxygen during combustion. The porosity $\phi$ is assumed to be constant. We assume that the oxygen transfer coefficient $D_{\text {Pap }}$ does not vary with time 
Table 1. Numerical values for the simulation of a cigarette for free horizontal smouldering and for smouldering on a substrate

\begin{tabular}{|c|c|c|c|c|}
\hline Name & Variable & Value & Dimension & Source \\
\hline Time & $t$ & variable & $\mathrm{s}$ & \\
\hline Position along tobacco rod & $x$ & variable & $\mathrm{m}$ & \\
\hline Tobacco rod temperature & $T$ & variable & $\mathrm{K}$ & \\
\hline Tobacco rod length & $L$ & 60 & $\mathrm{~mm}$ & \\
\hline Tobacco rod radius & $r_{0}$ & 4 & $\mathrm{~mm}$ & \\
\hline Tobacco rod heat conductivity & $\lambda$ & 0.066881 & $\mathrm{~W} / \mathrm{mK}$ & (7) \\
\hline Tobacco rod heat capacity & $c_{p}$ & 2341.9 & $\mathrm{~J} / \mathrm{kgK}$ & (13) \\
\hline Tobacco rod porosity & $\phi$ & 0.85 & 1 & (9) \\
\hline Heat transfer coefficient ${ }^{a}$ & $\alpha$ & $9.68 ; 17.44$ & $\mathrm{~W} / \mathrm{m}^{2} \mathrm{~K}$ & \\
\hline Emission number & $\varepsilon$ & 0.9 & 1 & (9) \\
\hline Stefan-Boltzmann constant & $\sigma$ & $5.67 \times 10^{-8}$ & $\mathrm{~W} /\left(\mathrm{m}^{2} \mathrm{~K}^{4}\right)$ & (14) \\
\hline Shape factor & $F$ & 0.17 & 1 & \\
\hline Combustion energy ${ }^{b}$ & $q$ & $8.08 \times 10^{6}$ & $\mathrm{~J} / \mathrm{kg}$ & $(12)$ \\
\hline Oxygen transfer coefficient & $D_{\text {Pap }}$ & 0.017 & $\mathrm{~m} / \mathrm{s}$ & \\
\hline Diffusion constant of tobacco rod & $D_{\text {Tob }}$ & not used & $\mathrm{m}^{2} / \mathrm{s}$ & \\
\hline Configuration factor for transfer coefficient ${ }^{a}$ & $\gamma$ & $1.00 ; 0.75$ & 1 & \\
\hline Mass fraction of oxygen in ambient air & $W_{\mathrm{O}_{2}, \infty}$ & 0.23 & $\mathrm{~kg} \mathrm{O}_{2} / \mathrm{kg}$ air & $(14)$ \\
\hline Mass fraction of oxygen in gas phase & $w_{\mathrm{O}_{2}}$ & variable & $\mathrm{kg} \mathrm{O}_{2} / \mathrm{kg}$ gas & \\
\hline Stoichiometric coefficient for oxygen ${ }^{b}$ & $k$ & 0.64 & 1 & $(12)$ \\
\hline Density of ambient air & $\rho_{\mathrm{Gas}, \infty}$ & 1.19 & $\mathrm{~kg} / \mathrm{m}^{3}$ & $(14)$ \\
\hline Density of gas & $\rho_{\mathrm{Gas}}$ & variable & $\mathrm{kg} / \mathrm{m}^{3}$ & \\
\hline Initial density of tobacco rod & $\rho_{\text {Tob, } \infty}$ & 263.83 & $\mathrm{~kg} / \mathrm{m}^{3}$ & \\
\hline Density of tobacco rod & $\rho_{\mathrm{Tob}}$ & variable & $\mathrm{kg} / \mathrm{m}^{3}$ & \\
\hline Density of burnt tobacco rod (ash) & $\rho_{\text {Ash }}$ & 39.57 & $\mathrm{~kg} / \mathrm{m}^{3}$ & $(8)$ \\
\hline Ambient temperature & $T_{\infty}$ & 296 & $\mathrm{~K}$ & \\
\hline Temperature for reaction & $T_{r}$ & 500 & $\mathrm{~K}$ & \\
\hline
\end{tabular}

${ }^{a}$ The left value is chosen for free smouldering, the right value for smouldering on the substrate.

${ }^{b}$ Values are per kg completely combustible tobacco (= ash excluded). The values per $\mathrm{kg}$ tobacco are $6.87 \times 10^{6} \mathrm{~J} / \mathrm{kg}$ and 0.544 , respectively.

but depends on the position. In the non-banded areas it is set to $0.017 \mathrm{~m} / \mathrm{s}$ and in the banded areas of the tobacco rod it varies between 0 and $0.006 \mathrm{~m} / \mathrm{s}$. The configuration factor $\gamma$ accounts for differences in the oxygen transport between free smouldering and smouldering on a substrate. For free smouldering it is set to 1 and for smouldering on a substrate it is set to 0.75 . These equations can be completed by a reaction model to calculate the change in tobacco density. Unfortunately, whenever a reaction model is included, the system of equations becomes rather stiff and the numerical simulation will be time-consuming. To circumvent this problem we make use of an additional observation. It has frequently been reported that the smouldering rate of cigarettes is limited by the availability of oxygen (15). Therefore we assume that in the smouldering zone the mass fraction of oxygen $w_{\mathrm{O}_{2}}$ and its derivatives are zero, so that the reaction rate is determined by the transport of oxygen into the cigarette. This leads us to an equation for the reaction rate in the smouldering zone. With these assumptions the oxygen transport equation [2] can be reformulated as

$$
0=\gamma D_{\text {Pap }} \phi \rho_{\mathrm{Gas}} \frac{2}{r_{0}} w_{\mathrm{O}_{2}, \infty}+k \frac{\partial \rho_{\mathrm{Tob}}}{\partial t}
$$

Hence we calculate the reaction rate by

$$
\frac{\partial \rho_{\mathrm{Tob}}}{\partial t}=\left\{\begin{array}{cl}
-2 \frac{\gamma D_{\mathrm{Pap}} \phi \rho_{\mathrm{Gas}} w_{\mathrm{O}_{2}, \infty}}{r_{0} k} & \text { if } T>T_{\mathrm{r}} \text { and } \rho_{\mathrm{Tob}}>\rho_{\text {Ash }} \\
0 & \text { else }
\end{array}\right.
$$

such that reactions occur whenever the temperature is sufficiently high and tobacco is still available.

The gas density $\rho_{\text {Gas }}$ depends on temperature and pressure. During smouldering, however, pressure differences relative to ambient air pressure are small compared to the relative temperature differences, and by assuming an ideal gas, we may calculate the density by

$$
\rho_{\text {Gas }}=\rho_{\text {Gas }, \infty} \frac{T}{T_{\infty}}
$$

which eliminates the density as a variable. 
As boundary conditions we demand that no heat conduction takes place over the system boundaries, that is

$$
\frac{\partial T(0, t)}{\partial x}=\frac{\partial T(L, t)}{\partial x}=0
$$

for all $t \geq 0$. These boundary conditions do not matter much, as soon as the smouldering cone is sufficiently far away from the system boundaries. No boundary condition is needed for the tobacco density $\rho_{\mathrm{Tob}}$, as the density is not differentiated with respect to the spatial coordinate $x$. The initial conditions are given for the temperature by

$$
T(x, 0)= \begin{cases}T_{\infty} & \text { if } \quad x \leq L-3 \mathrm{~mm} \\ 1300 & \text { else. }\end{cases}
$$

This means, that the entire tobacco rod is at room temperature with the exception of the first $3 \mathrm{~mm}$, which are heated to $1300 \mathrm{~K}$. This represents the lighting process and starts the smouldering of the cigarette. For the tobacco density the initial conditions are

$$
\rho_{\mathrm{Tob}}(x, 0)=\rho_{\mathrm{Tob}, \infty} \text { for all } x \in[0, L] .
$$

Once the numerical simulation of the model is completed the cigarette is assumed extinguished, if the maximum temperature along the tobacco rod is smaller than $T_{\mathrm{r}}$, which means that the reaction rate is zero everywhere.

It is clear that this model contains many simplifications, but it has the advantage that it is on the one hand sufficiently simple to be simulated quickly and on the other hand still sufficiently comprehensive to describe the most important thermodynamic effects.

\section{VERIFICATION OF THE MODEL}

The temperature profile of a smouldering cigarette with the nominal parameters according to Table 1 is shown for the free-burn test in Figure 1a and for the ignition strength test in Figure $1 \mathrm{~b}$. The maximum temperature of about $1000 \mathrm{~K}$ is a reasonable value for many cigarettes and agrees with values documented in the literature (7). Also the shape of the temperature profile and the length of the smouldering cone agree well with experimental data (16). To match the linear burn rate of smouldering cigarettes with the simulation results, the linear burn rate was determined for a typical European cigarette brand without bands on the cigarette paper. On 10 cigarettes the time was measured until the char line had moved a distance of $35 \mathrm{~mm}$ with a starting point 15 $\mathrm{mm}$ from the cigarette tip. The measurement was repeated for free horizontal smouldering and for smouldering on 10 layers of Whatman no. 2 filter paper. For free smouldering the linear burn rate was found to be $6.05 \pm 0.36 \mathrm{~mm} / \mathrm{min}$ and on the filter paper $4.04 \pm 0.34 \mathrm{~mm} / \mathrm{min}$ were measured. The heat transfer coefficient $\alpha$ and the configuration factor $\gamma$ for the oxygen transfer coefficient were adjusted such that the simulated linear burn rates matched the experimental data. To evaluate the predictive quality with respect to the thermodynamic behaviour, the heat losses due to convection and radiation were calculated by integration along the tobacco rod and they were found to be in good agreement with the results from MIURA (17) who reported that the heat losses by radiation and convection during smouldering are approximately equal.

As there is a good agreement with experimental data with respect to temperature, linear burn rates and heat losses we may assume that this model reasonably reflects the real thermodynamic behaviour of smouldering cigarettes.

There are, however, a few effects which could not be accounted for in the model. For example, the porosity of the tobacco rod will change during smouldering and also the oxygen transfer coefficient of the bands and of the cigarette paper will change once the paper is heated. This limits the quantitative accuracy of the results.

To check whether a cigarette will extinguish, simulations were repeated with a cigarette with two $7 \mathrm{~mm}$ wide bands on the cigarette paper and a spacing of $25 \mathrm{~mm}$ from band centre to band centre. The oxygen transfer coefficient of the bands was set to $0.2 \mathrm{~cm} / \mathrm{s}$. The temperature profiles for the free-burn test are shown in Figure 1c and for the ignition strength test in Figure 1d. We see that with this model it is possible to simulate self-extinguishment and that there exist band geometries and oxygen transfer coefficients such that it is possible to pass both tests simultaneously. Consequently, it makes sense to determine the appropriate range of oxygen transfer coefficients for various cigarette parameters.

\section{STATISTICAL CONSIDERATIONS}

Due to variations in the cigarette properties a randomly chosen cigarette will pass the ignition strength test or the free-burn test only with a certain probability. Let $\boldsymbol{z} \in \boldsymbol{R}^{N}$ denote a vector of cigarette model parameters. In order to predict the probability we define a function

$$
f(z)=\left\{\begin{array}{l}
1 \text { if a cigarette with parameters } z \text { passes both tests } \\
0 \text { else }
\end{array}\right.
$$

and the probability that a cigarette passes the tests can then be calculated by evaluating the integral

$$
P_{\text {pass }}=\int_{R^{N}} f(\boldsymbol{z}) P(\boldsymbol{Z}=\boldsymbol{z}) d V
$$

where $P(\boldsymbol{Z}=\boldsymbol{z})$ denotes the probability that the random cigarette parameters $\boldsymbol{Z}$ assume the value $\boldsymbol{z}$. To keep the numerical complexity at a reasonable level we will consider the variation of only two parameters at a time. One parameter is always the oxygen transfer coefficient $D_{\text {Pap }}$ through the bands on the cigarette paper and the second parameter is either the initial tobacco density, the heat capacity, the width of the bands or the heat of combustion. We may safely assume that these parameters are independently distributed and we will, without further investigation, accept the hypothesis that they are also normally distributed. Let $z=\left[\begin{array}{ll}z_{1} & z_{2}\end{array}\right]^{T}$ be our parameter vector, where $z_{i}$ is normally distributed with mean $\mu_{i}$ and standard deviation $\sigma_{i}$, $i \in\{1,2\}$, then we can reformulate the probability for passing the tests in Eqn. [10] by 

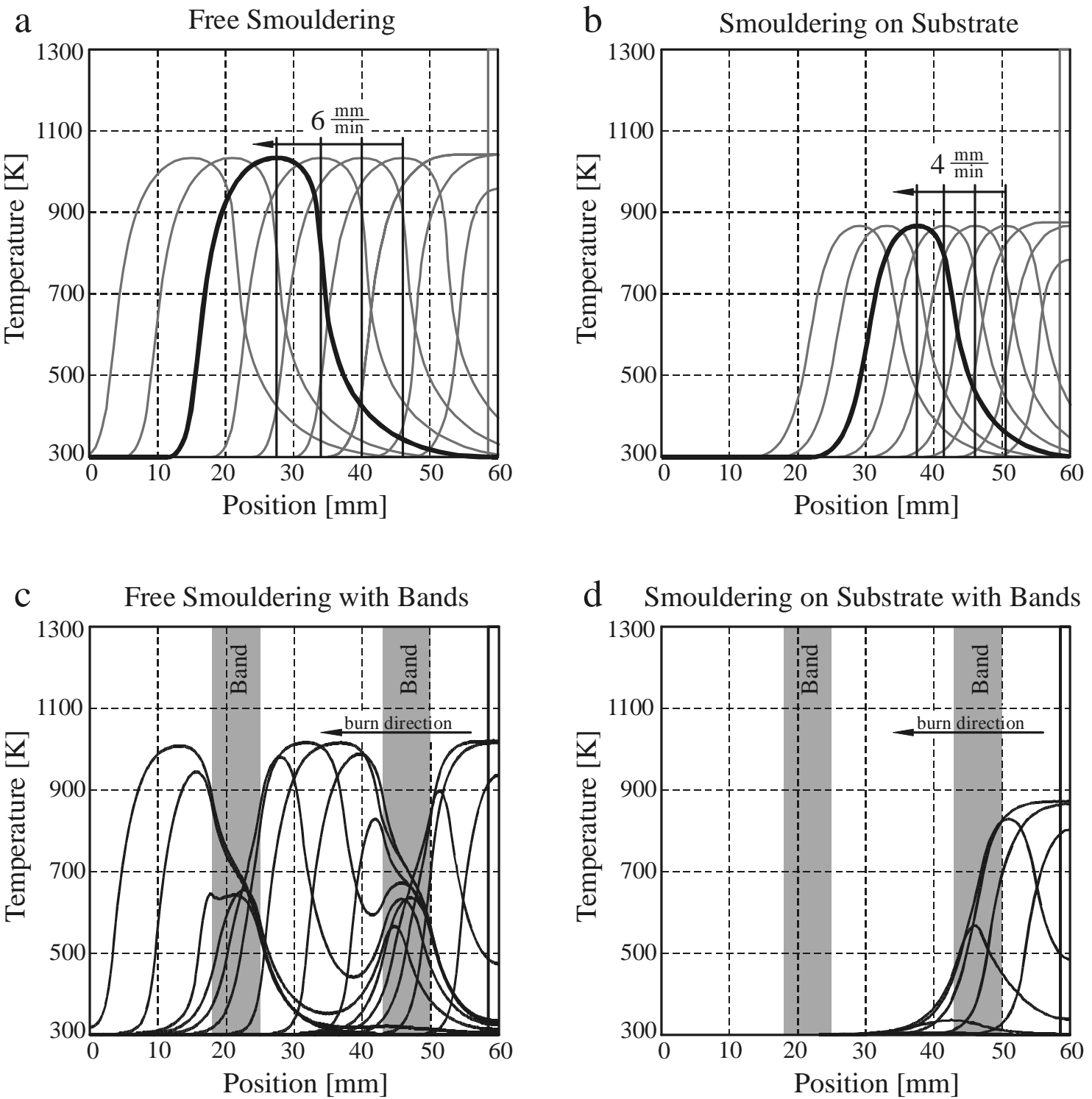

d Smouldering on Substrate with Bands

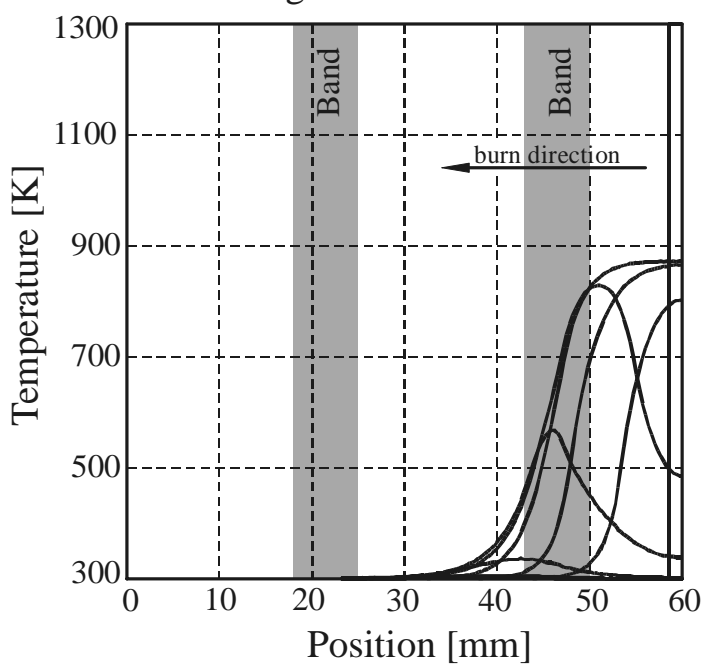

Figure 1. Simulated temperature profiles of a cigarette smouldering freely (a), on a substrate (b), freely with a cigarette paper with bands (c) and on a substrate with a cigarette paper with bands (d).

$$
\begin{aligned}
P_{\text {pass }}\left(\mu_{1}, \mu_{2}\right)= & \frac{1}{2 \pi \sigma_{1} \sigma_{2}} \iint_{R^{2}} f\left(\left[z_{1} z_{2}\right]^{T}\right) \\
& \exp \left(-\frac{\left(z_{1}-\mu_{1}\right)^{2}}{2 \sigma_{1}^{2}}-\frac{\left(z_{2}-\mu_{2}\right)^{2}}{2 \sigma_{2}^{2}}\right) d z_{1} d z_{2}
\end{aligned}
$$

This integral will be evaluated numerically.

For the numerical evaluation not only the mean values of the parameters but also their standard deviations are needed. For the initial tobacco density the same 10 cigarettes as were used for the measurement of the linear burn rate were weighed and a mass of $940.5 \pm 46.0 \mathrm{mg}$ was found. While, of course, the total variation in mass cannot be attributed to variations in tobacco density alone, we assume that it accounts for a large part of it and consequently use $2.45 \%$ as a coefficient of variation for the calculations.

The standard deviation for the heat of combustion was determined from the measurements reported in (12), Figure 3 , and the coefficient of variation will be set to $4.2 \%$.
The coefficient of variation of the heat capacity can be derived from Figures 2 and 7 in (13), by assuming that the change in heat capacity is caused by a variation of the relative humidity of the ambient air, which consequently influences the moisture content of the tobacco. For a relative humidity range of $60 \pm 5 \%$, as required by the standard (18), a coefficient of variation of $3.4 \%$ can be obtained.

For the coefficient of variation of the width of the bands on the cigarette paper a value of $5 \%$ was assumed. Finally, the coefficient of variation of the oxygen transfer coefficient was set to $0 \%, 2 \%, 5 \%$ and $10 \%$, to assess its effect.

Let us assume that a cigarette passes both tests with probability $P_{\text {pass }}$. The probability $P_{\text {total }}$ that at least 30 out of 40 cigarettes pass both tests is then given by

$$
P_{\text {total }}=\sum_{i=0}^{10}\left(\begin{array}{c}
40 \\
i
\end{array}\right)\left(1-P_{\text {pass }}\right)^{i} P_{\text {pass }}^{40-i}
$$


This probability should be higher than, for example, 0.99 (0.95). Consequently, we can solve Eqn. [12] and obtain

$$
P_{\text {pass }}>0.8718 \quad(0.8375)
$$

which means that a single cigarette should pass both tests with a probability of at least $0.8718(0.8375)$. By setting $P_{\text {pass }}$ to the value in inequality [13] and returning it to Eqn. [12], we obtain that a mean of 34.87 (33.50) cigarettes will pass the tests with a standard deviation of 2.11 (2.33) cigarettes. Notice that a relatively high coefficient of variation of $6.05 \%(6.95 \%)$ is inherent to the testing procedure.

\section{NUMERICAL DETAILS}

The tobacco rod was divided into $N=240$ elements with a width of $\Delta x=0.25 \mathrm{~mm}$ and the temperature and tobacco density were spatially discretised by

$$
\left.\begin{array}{rl}
T_{i} & =T\left(x_{i}, t\right) \\
\rho_{\mathrm{Tob}, i} & =\rho_{\mathrm{Tob}}\left(x_{i}, t\right)
\end{array}\right\} \text { with } x_{i}=i \cdot \Delta x-\frac{\Delta x}{2}, i=\{1, \ldots, N\} .
$$

The initial conditions [7] and [8] were discretised in a similar manner.

The spatial derivative in the energy Eqn. [1] was approximated by central differences, that is,

$$
\frac{\partial^{2} T\left(x_{i}, t\right)}{\partial x^{2}} \approx \frac{\delta^{2} T_{i}}{\delta x^{2}}=\frac{T_{i-1}-2 T_{i}+T_{i+1}}{\Delta x^{2}}, i=\{2, \ldots, N-1\}
$$

and the spatial derivatives at the boundaries, which are needed in the boundary conditions [6] for the temperature, were approximated by forward and backward differences, respectively. Taking all together we obtain an explicit coupled system of 480 ordinary differential equations with respect to time

$$
\begin{gathered}
\frac{\partial T_{i}}{\partial t}=\frac{\lambda}{\rho_{\mathrm{Tob}, i} c_{p}} \frac{\delta^{2} T_{i}}{\delta x^{2}}+\frac{\alpha}{\rho_{\mathrm{Tob}, i} c_{p}} \frac{2}{r_{0}}\left(T_{\infty}-T_{i}\right) \\
+\frac{\varepsilon \sigma F}{\rho_{\mathrm{Tob}, i} c_{p}} \frac{2}{r_{0}}\left(T_{\infty}^{4}-T_{i}^{4}\right)-\frac{q}{\rho_{\mathrm{Tob}, i} c_{p}} \frac{\partial \rho_{\mathrm{Tob}, i}}{\partial t} \\
\frac{\partial \rho_{\mathrm{Tob}, i}}{\partial t}=\left\{\begin{array}{cc}
-2 \frac{\gamma D_{\mathrm{Pap}, i} \phi \rho_{\mathrm{Gas}, \infty} T_{\infty} w_{O_{2}, \infty}}{T_{i} r_{0} k} & \text { if } T_{i}>T_{r} \text { and } \rho_{\mathrm{Tob}, i}>\rho_{\mathrm{Asb}} \\
0 & \text { else }
\end{array}\right.
\end{gathered}
$$

By collecting the discretised temperature and density values in two vectors, $\boldsymbol{T}^{T}=\left[\begin{array}{llll}T_{1} & T_{2} & \cdots & T_{N}\end{array}\right]$ and $\rho_{\text {Tob }}^{T}=\left[\begin{array}{llll}\rho_{\text {Tob, } 1} & \rho_{\text {Tob, } 2} & \ldots & \rho_{\text {Tob, }, N}\end{array}\right]$, the two Eqns. [14] and [15] can be written as

$$
\left[\begin{array}{c}
\frac{d \boldsymbol{T}}{d t} \\
\frac{d \rho_{\mathrm{Tob}}}{d t}
\end{array}\right]=\left[\begin{array}{l}
f_{T}\left(t, T, \rho_{\mathrm{Tob}}\right) \\
f_{\rho}\left(t, T, \rho_{\mathrm{Tob}}\right)
\end{array}\right] .
$$

This system of ordinary differential equations can be numerically integrated by standard methods such as, e.g. the Runge-Kutta method. Here a second-order Runge-Kutta method with automatic step-size adjustment was used as implemented in the ode2 3 function in MATLAB 6.5. The integration time was $600 \mathrm{~s}$ and the error tolerances were set to their default values. A single simulation takes about $10 \mathrm{~s}$ on a standard desktop computer with Pentium 4 processor and a $3 \mathrm{GHz}$ clock rate. Convergence towards a gridindependent solution was checked by varying the number of elements.

A threshold value for the oxygen transfer coefficient of the bands was determined for 40 evenly distributed points in an interval of $\pm 30 \%$ of the nominal value from Table 1 for initial tobacco density, heat capacity and heat of combustion. For the width of the bands values between $0.5 \mathrm{~mm}$ and $10 \mathrm{~mm}$ were evaluated in steps of $0.25 \mathrm{~mm}$. To determine a threshold value for the oxygen transfer coefficient for each parameter set a bisection method with a relative error tolerance of $10^{-4}$ was used. This procedure delivers the function $f(z)$ in Eqn. [9].

The double integral in Eqn. [11] is evaluated numerically with the dblquad function in MATLAB 6.5 with the default relative error tolerance of $10^{-6}$. The domain of integration is $\left[\mu_{1}-5 \sigma_{1}, \mu_{1}+5 \sigma_{1}\right] \times\left[\mu_{2}-5 \sigma_{2}, \mu_{2}+5 \sigma_{2}\right]$.

\section{RESULTS}

The left-hand side in Figures 2 to 5 shows the contour lines of the probability for a randomly chosen cigarette to pass both tests. It has to be noted that the values on the $x$ and $y$ axis are the mean values of the normally distributed model parameters and the coefficients of variation of the parameters were set to the values given above. For the oxygen transfer coefficient the coefficient of variation was set to $10 \%$ in the contour line diagrams.

In Figure 2 the heat of combustion was varied between $\pm 30 \%$ of the nominal value. The same interval also applies to the initial tobacco density, Figure 3, and the tobacco rod heat capacity, Figure 4. Finally, the width of the bands on the paper was varied from $0.5 \mathrm{~mm}$ up to $10 \mathrm{~mm}$ and the corresponding probability contour lines are shown in Figure 5. On the right-hand side of each of the Figures 2 to 5 a cross section A-A at the nominal parameter values from Table 1 is shown for various coefficients of variation of the oxygen transfer coefficient of $0,2,5$ and $10 \%$.

\section{DISCUSSION}

As can be seen in Figures 2 to 5 a high oxygen transfer coefficient will in general prevent the cigarette from extinguishing even during smouldering on a substrate, because sufficient oxygen is transported to the smouldering cone. Such cigarettes will fail the ignition strength test. On the other hand a too low oxygen transfer coefficient will lead to self-extinguishment during free smouldering. The region between these two thresholds is quite narrow. In Figure 2, left-hand side, we see that with increasing heat of combustion the oxygen transfer coefficient needs to 

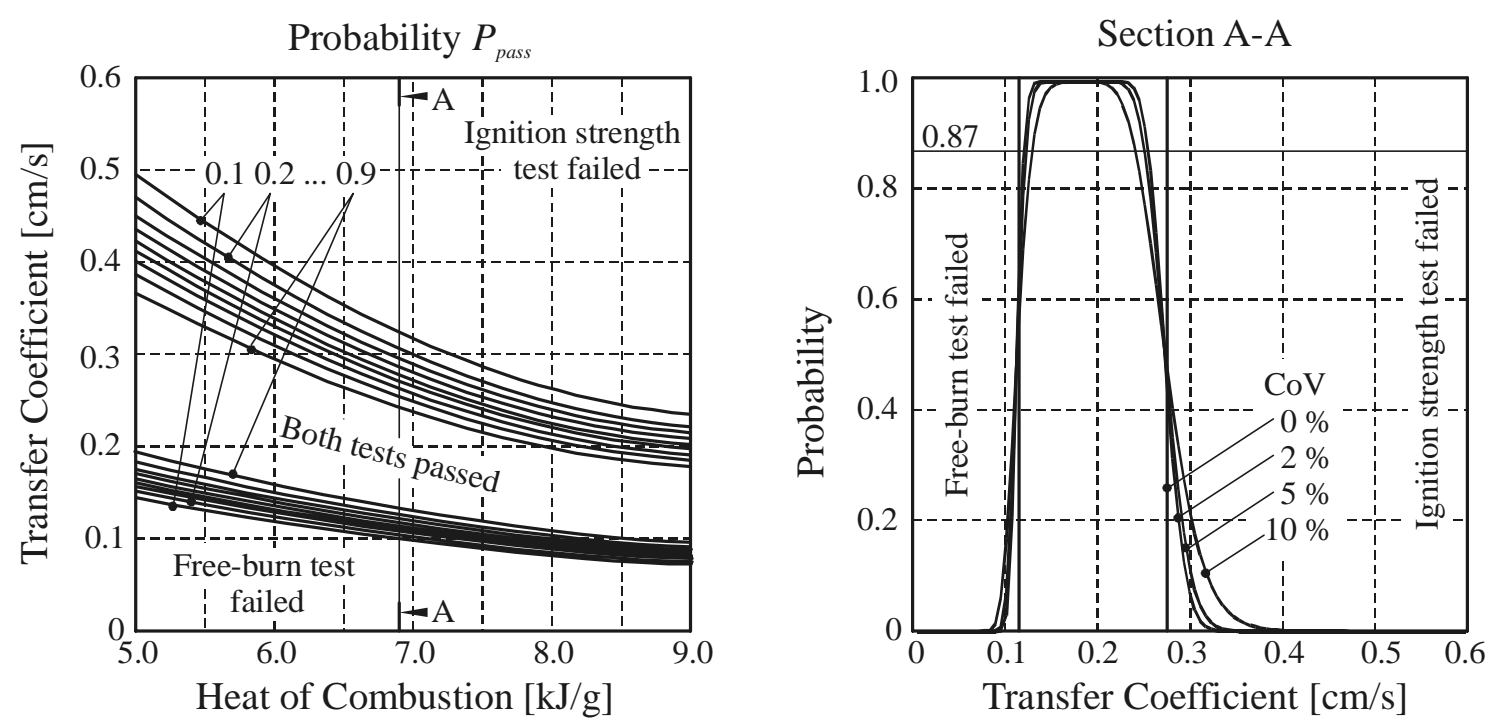

Figure 2. The probability for passing the free-burn and the ignition strength test of a randomly chosen cigarette. The oxygen transfer coefficient of the bands and the heat of combustion were assumed to be normally distributed, their mean values are given on the $y$-axis and $x$-axis, respectively. The section A-A on the right-hand side shows a cross-section at a typical heat of combustion with different coefficients of variation (CoV) for the oxygen transfer coefficient of $0 \%, 2 \%, 5 \%$ and $10 \%$.
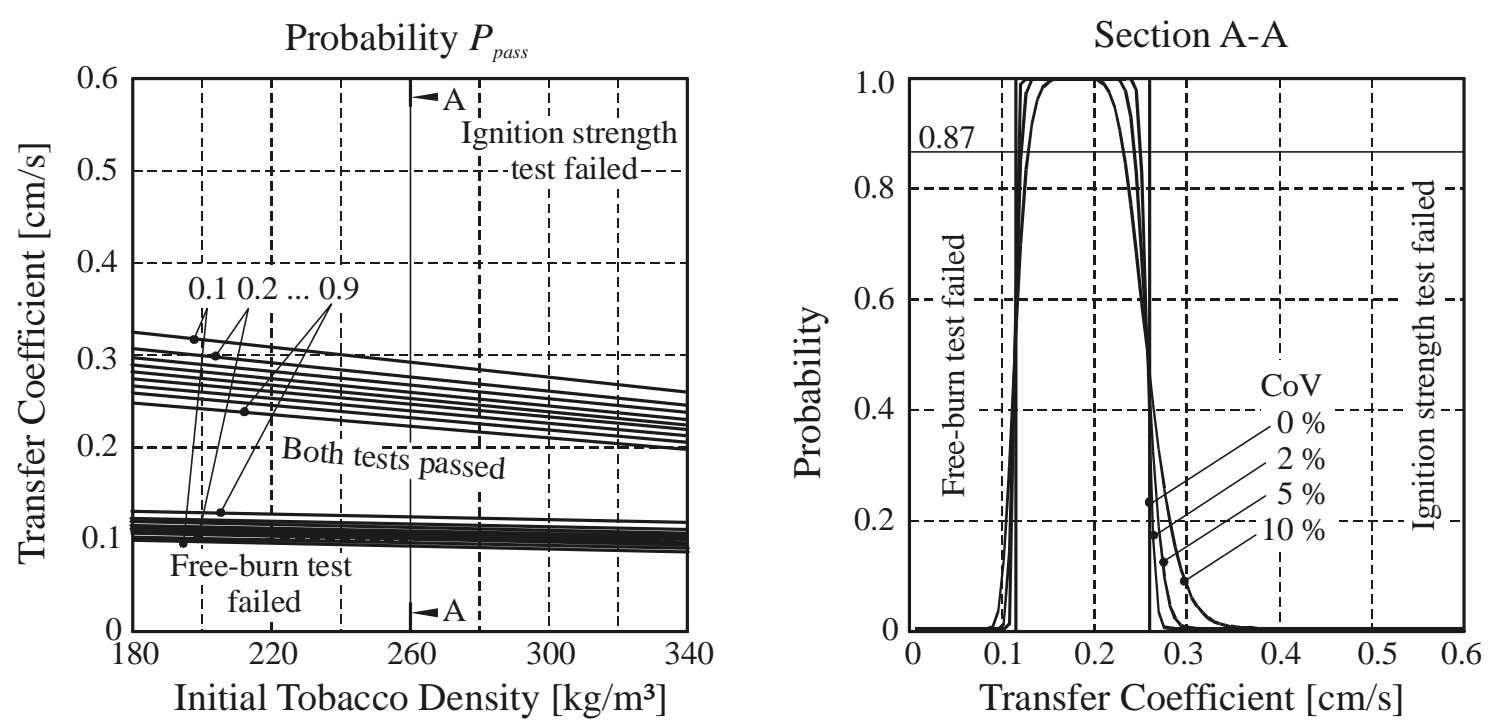

Figure 3. The probability for passing the free-burn and the ignition strength test of a randomly chosen cigarette. The oxygen transfer coefficient of the bands and the initial tobacco density were assumed to be normally distributed, their mean values are given on the $y$-axis and $x$-axis, respectively. The section A-A on the right-hand side shows a cross-section at a typical initial tobacco density with different coefficients of variation (CoV) for the oxygen transfer coefficient of $0 \%, 2 \%, 5 \%$ and $10 \%$.

become smaller which is quite reasonable, as increased heat of combustion means that a lower reaction rate may still provide enough energy to sustain the smouldering process. It agrees well with practical experience that a cigarette with an oxygen transfer coefficient between $0.13 \mathrm{~cm} / \mathrm{s}$ and 0.23 $\mathrm{cm} / \mathrm{s}$ will pass the tests, but we also note that this interval is quite small.

The initial tobacco density, Figure 3, and the heat capacity of the tobacco rod, Figure 4, have only a minor influence on the appropriate interval of the oxygen transfer coefficient. With increasing initial tobacco density the required oxygen transfer coefficient decreases slightly, which agrees with expectations and basic physical considerations. The influence of the heat capacity is even smaller. An increased heat capacity causes the tobacco to heat up more slowly, but also slows down the cooling of the tobacco rod, such that the overall effect on the self-extinguishment is rather neutral.

In contrast to the tobacco density and the heat capacity, the width of the bands shows an especially pronounced effect on the self-extinguishment of cigarettes. Below a width of approximately $1.5 \mathrm{~mm}$ the cigarette will never extinguish in the ignition strength test even if we reduce the oxygen 

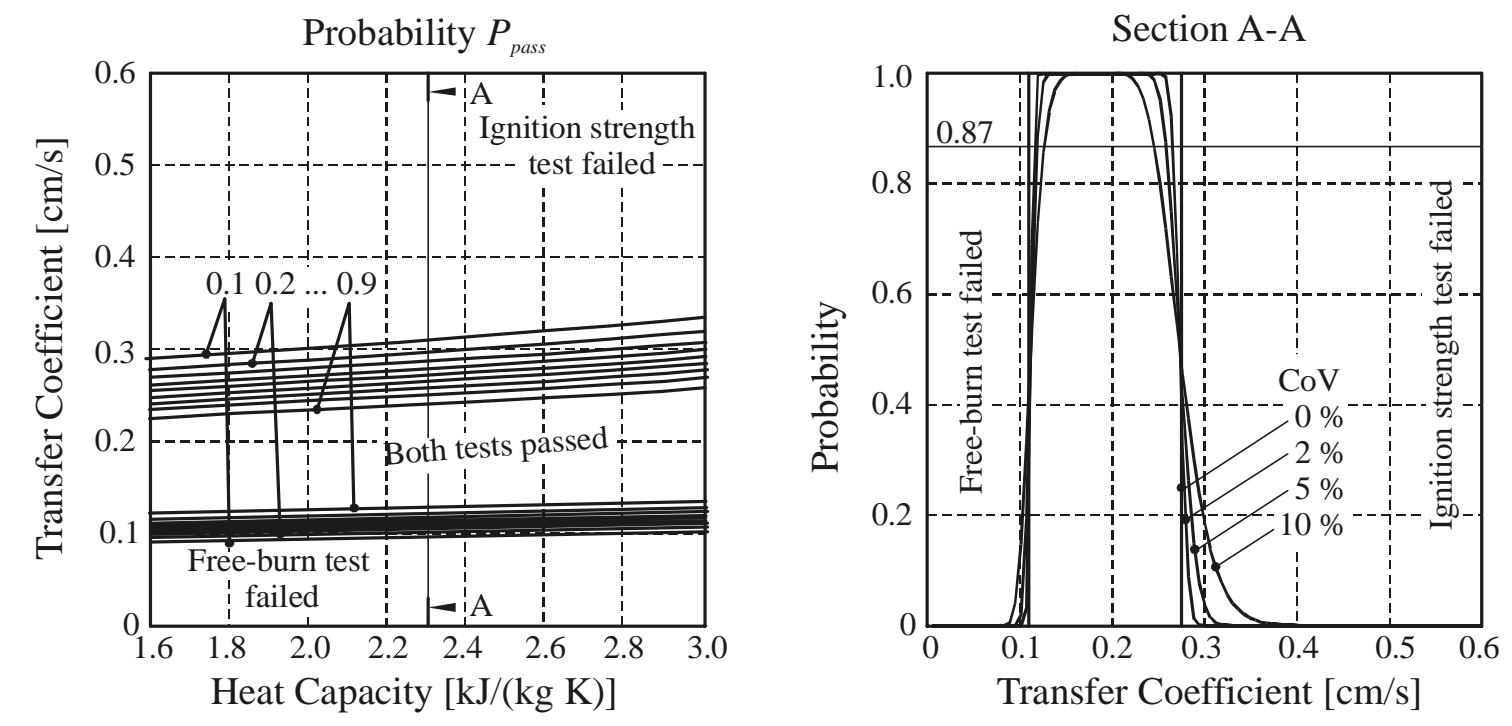

Figure 4. The probability for passing the free-burn and the ignition strength test of a randomly chosen cigarette. The oxygen transfer coefficient of the bands and the tobacco rod heat capacity were assumed to be normally distributed, their mean values are given on the $y$-axis and $x$-axis, respectively. The section A-A on the right-hand side shows a cross-section at a typical heat capacity with different coefficients of variation (CoV) for the oxygen transfer coefficient of $0 \%, 2 \%, 5 \%$ and $10 \%$.
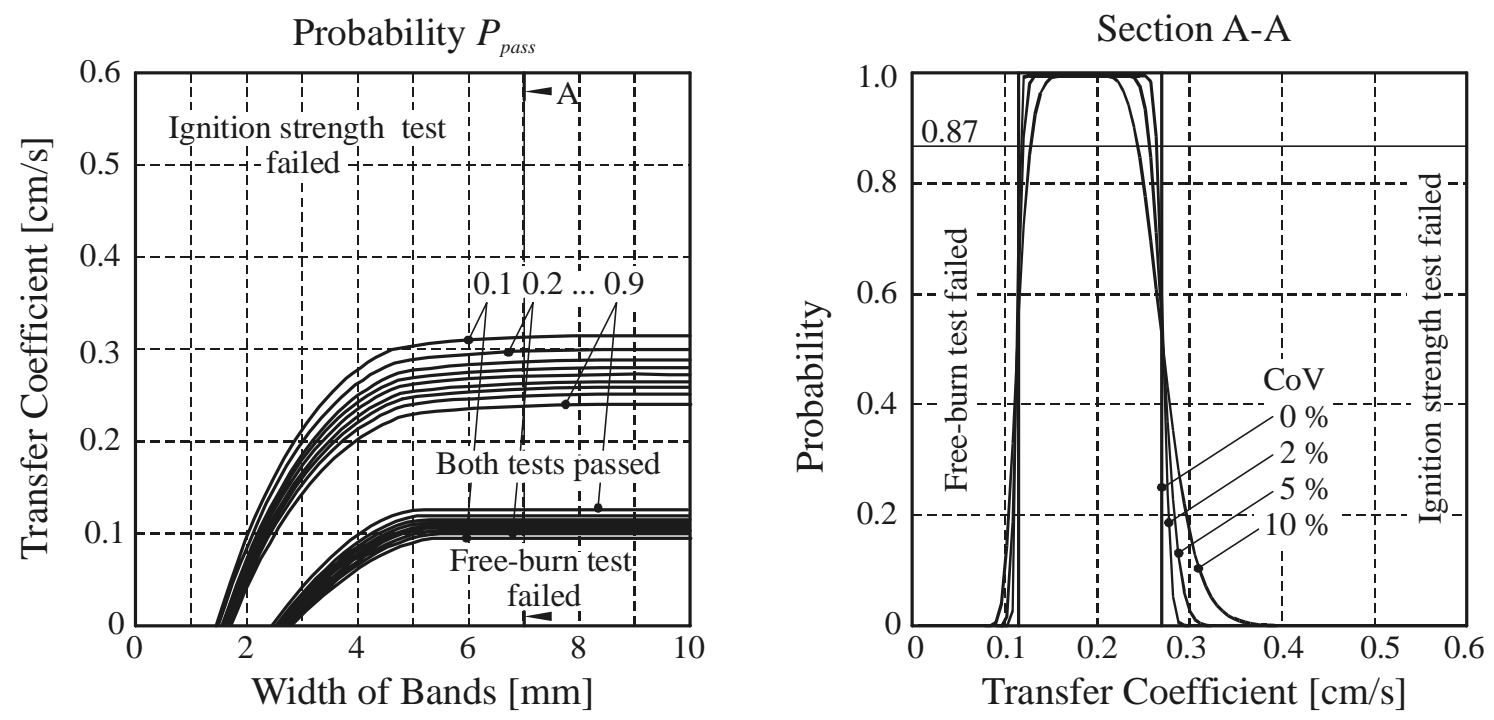

Figure 5. The probability for passing the free-burn and the ignition strength test of a randomly chosen cigarette. The oxygen transfer coefficient of the bands and the width of the bands were assumed to be normally distributed, their mean values are given on the $y$ axis and $x$-axis, respectively. The section A-A on the right-hand side shows a cross-section at a width of $7 \mathrm{~mm}$ with different coefficients of variation $(\mathrm{CoV})$ for the oxygen transfer coefficient of $0 \%, 2 \%, 5 \%$ and $10 \%$.

transfer coefficient of the bands to zero. Likewise below a width of $3 \mathrm{~mm}$ the cigarette will never extinguish during free smouldering. As we have neglected oxygen transport along the tobacco rod, the reaction rate in the banded part, Eqn. [4], will be zero if we set the oxygen transfer coefficient of the band to zero. In spite of this the smouldering process can still continue, because heat is conducted along the cigarette axis, such that combustion starts again in the non-banded part of the cigarette. With a more sophisticated model, which includes the transport of oxygen along the tobacco rod, e.g. by diffusion or convection, also the tobacco in the banded part of the cigarette would be combusted and it would become even easier for the smouldering cone to pass through a banded area without oxygen supplied through the band. Consequently, the proposed model underestimates the minimum bandwidth to achieve self-extinguishment.

For widths up to $5 \mathrm{~mm}$ the required range of oxygen transfer coefficients increases and shifts towards higher values. Above $5 \mathrm{~mm}$ this range is almost independent of the width of the bands because for these high widths a stationary smouldering process needs to be sustained while the smouldering cone passes through the band on the cigarette paper. 
From this we may conclude that the diagrams in Figures 2 to 4 , which were calculated for a width of $7 \mathrm{~mm}$, are also in good approximation valid for all widths above $5 \mathrm{~mm}$. In this respect the choice of 6 or $7 \mathrm{~mm}$ wide bands, as they are typically found on commercial reduced ignition propensity cigarettes, is reasonable to ensure stability of the test results with respect to small variations in the width of the bands. In the sections A-A in Figures 2 to 5 a horizontal line at a probability of 0.87 is drawn to visualize the appropriate range of oxygen transfer coefficients, such that with a probability of 0.99 thirty or more cigarettes out of a sample of 40 pass the tests. We see that considering normally distributed, instead of single-valued, cigarette parameters significantly reduces the appropriate range of oxygen transfer coefficients. In Figure 2, the interval of appropriate oxygen transfer coefficients for a coefficient of variation of $10 \%$ is only about two thirds of the interval for a coefficient of variation of $0 \%$. The situation is similar for the other cigarette parameters in Figures 3 to 5 .

The main conclusions from this investigation are therefore as follows. There exists an interval of oxygen transfer coefficients such that cigarettes pass the ignition strength test and the free-burn test. This interval depends strongly on the width of the bands and on the heat of combustion of the tobacco. The dependence on the heat capacity of the tobacco rod and on the initial tobacco density is less strong. Taking into account that cigarette parameters are subject to statistical variations reduces the appropriate interval of oxygen transfer coefficients by about one third.

Consequently, a reduced variation of cigarette parameters and the appropriate choice of the oxygen transfer coefficient are both equally important steps toward designing cigarette papers for cigarettes with reduced ignition strength.

\section{REFERENCES}

1. ASTM E 2187-02b: Standard method for measuring the ignition strength of cigarettes, American Society for Testing and Materials, ASTM Int., 2002.

2. Eitzinger, B.: Design guidelines for papers for low ignition propensity cigarettes; Presentation at the CORESTA congress, Kyoto, Abstract PT9, 2004.

3. Durocher, D.F., T. Kraker, J.T. Wanna, and W. Codwise: Using paper diffusion measurements to assess the ignition strength of cigarettes; Presentation at the CORESTA meeting of the smoke science and product technology study groups, Stratford-uponAvon, Abstract SSPT12, 2005.

4. Norman, A.B., J.C. Caudle, and C.W. Henderson: Measurement of gas diffusion capacity of cigarette papers; Beitr. Tabakforsch. Int. 21 (2005) 425-434.

5. Parrish, M.E., and C.N. Harward: Measurement of formaldehyde in a single puff of cigarette smoke using tunable diode laser infrared spectroscopy; Appl. Spectroscopy 54 (2000) 1665-1677.
6. Li, S., J.L. Banyasz, M.E. Parrish, J. Lyons-Hart and K.H. Shafer: Formaldehyde in the gas phase of mainstream cigarette smoke; J. Anal. Appl. Pyrolysis 65 (2002) 137-145.

7. Chen, P.: A mathematical model of cigarette smoldering process; Beitr. Tabakforsch. Int. 20 (2002) 265-271.

8. Eitzinger, B. and S. Pirker: Numerical simulation of a cigarette during smoking; Beitr. Tabakforsch. Int. 21 (2005) 402-416.

9. Rostami, A., J. Murthy, and M. Hajaligol: Modeling of a smoldering cigarette; J. Anal. Appl. Pyrolysis 66 (2003) 281-301.

10. Muramatsu, M.: An approach to modelling a burning cigarette; Beitr. Tabakforsch. Int. 21 (2005) 286-293.

11. Liu, C.: A smouldering cigarette on 10-layer Whatman filter paper substrate: Steady-state temperature distribution; Presentation at the CORESTA meeting of the smoke science and product technology study groups, Stratford-upon-Avon, Abstract SSPT13, 2005.

12. Waymack, B.E., D.S. Kellogg, D.D. McRae, and R.W. Dwyer: Watts in a cigarette: Thermophysical properties of smoldering cigarettes; Tob. Sci. 41 (1997) 74-81.

13. Banyasz, J.L.: The thermodynamics of tobacco-water interactions; Beitr. Tabakforsch. Int. 18 (1999) 189-204.

14. Weast, R.C.: CRC Handbook of Chemistry and Physics, 64th edition, CRC Press, Florida, 1984.

15. Baker, R.R., and K.D. Kilburn: The distribution of gases within the combustion coal of a cigarette; Beitr. Tabakforsch Int. 7 (1973) 79-87.

16. Muramatsu, M., Y. Obi, T. Fukuzumi, and T. Keii: Influence of continuous puff velocity on combustion rate, temperature and temperature distribution in cigarettes; Nippon Nogei Kagaku Kaishi 46 (1972) 569-575.

17. Miura, K., A. Nagao, and K. Ueyama: Heat emission from a burning cigarette; Beitr. Tabakforsch. Int. 19 (2001) 245-250.

18. ISO 3402:1991: Tobacco and tobacco products Atmosphere for conditioning and testing; International Organization for Standardization, Geneva, 1991.

Address for correspondence:

Bernhard Eitzinger

WFT Research

Fabrikstraße 20

4050 Traun

e-mail: bernhard.eitzinger@traun.tbggroup.com 